\title{
Complications in AVM Surgery
}

\author{
Marco Cenzato, Davide Boeris, Maurizio Piparo, \\ Alessia Fratianni, Maria Angela Piano, Flavia Dones, \\ Francesco M. Crisà, and Giuseppe D’Aliberti
}

Surgery of cerebral arteriovenous malformations (AVM) is considered to be high-risk. This means that the risk of having complications during or soon after surgery is substantially elevated. This article describes the possible peri-operative complications for surgery of arteriovenous malformations and some suggestions to avoid their onset.

Brain malformation surgery has predominantly three kinds of complications that may result in possible neurological deficits for the patient:

1. Direct lesion of eloquent areas.

2. Postoperative bleeding due to the presence of a residual that has not been removed during surgery.

3. Postoperative hyperemia.

\section{Direct Lesion of an Eloquent Area}

Defining the limits between what is eloquent and what is not eloquent is not always so simple. Traditionally, eloquence has been referred to the cortical areas assigned to a specific function, essentially the motor areas, the areas of language and visual function, in addition, of course, to the brain stem and the deep structures. Magnetic resonance imaging with its high definition allows us to accurately understand the cortical areas affected by the arteriovenous malformation and the contiguous ones that may be damaged by surgery.

Functional resonance in arteriovenous malformations is questionable [1] and probably not reliable, because the excessive flow surrounding the AVM can alter the BOLD

M. Cenzato $(\bowtie) \cdot$ D. Boeris $\cdot$ M. Piparo $\cdot$ A. Fratianni

M. A. Piano · F. Dones · F. M. Crisà · G. D' Aliberti

Department of Neurosurgery, Grande Ospedale Metropolitano

Niguarda, Piazza dell'Ospedale Maggiore, Milan, Italy

Department of Neuroradiology, Grande Ospedale Metropolitano

Niguarda, Piazza dell'Ospedale Maggiore, Milan, Italy

e-mail: marco.cenzato@ospedaleniguarda.it effect. Transcranial magnetic stimulation may be a more precise method to identify the eloquent function. [2].

A malformation that affects eloquent cortical areas is hardly indicated as susceptible to surgical treatment. In these cases, the use of the Gamma Knife is the preferred alternative to surgery $[3,4]$.

Concerning eloquence, until a decade ago, white matter did not deserve great attention from neurosurgeons. Over the last decade the study of magnetic resonance with tractography allowed a more precise definition of the deep tracts of white matter $[5,6]$ and how eloquent they are. Before the introduction of the non-stick bipolar, one of the biggest problems to deal with, during arteriovenous malformations surgery, was to control the bleeding from the deep medullary vessels. That typically comes from the deep of the white matter [7]. These deep medullary vessels were extremely challenging to coagulate and required a meticulous and patient coagulation technique that was often laborious and difficult to obtain. Managing these fragile vessels was difficult because of the disproportion between the size of the vessel and the thickness of the protein wall. These vessels must often be pursued in the depth of the white substance to obtain a secure hemostasis. This often caused a damage of eloquent white matter tracts. Conventional bipolar forceps were effective only within a narrow range of humidity obtained by the irrigation of the surgical field. An excessive washing made the coagulation ineffective, while an insufficient washing led to an adhesion of the vessel to the tips of the bipolar forceps with subsequent rupture.

Today the hemostasis techniques are significantly improved. The introduction of the non-stick bipolar permits a more effective coagulation and does not require irrigation (dry coagulation). This allows the surgeon to be more effective at lower-current intensities without sticking the wall of the fragile deep vessels to the tip of the bipolar.

The use of non-stick dry coagulation, possibly in association with the "dirty coagulation" described by Hernesniemi, now makes coagulation of these medullary vessel easier and 
more effective. Dirty coagulation is a technique that, when the vessel wall is very thin, uses a small part of brain tissue adjacent to the vessel to increase the amount of protein to be subjected to coagulation [8]. This changed the risk of damaging eloquent deep white matter and permits more selective excision of the arteriovenous malformation within the interface malformation-brain tissue. We have found also that Thulium laser proved to be very useful in coagulating these very fragile deep vessels. It is a very versatile tool that allows a coagulation of the vessels without direct contact [9]. We prefer to avoid the use of contact hemostatic agents in AVM surgery, as often postoperative bleeds are related to residues and cannot be avoided with overlying hemostatic agents that can actually cause the spread of the bleeding into the parenchyma instead of the subarachnoid space. If a vessel has to bleed, it is preferable for the blood to spill in the cavity rather than within the brain.

Moreover, in the last few years the strict interaction with neuroradiologists promoted the selective use of presurgical embolization to close specific deep vessels that we anticipate will be difficult to reach during the excision of the AVM, instead of a massive nidus embolization. The previous strategy of embolizing the nidus with Onyx through the large feeders keeps the deep feeders open, often with an increased flow, complicating the control of bleeding [10]. Selectively embolizing the deep feeders reduces the need to follow a bleeding vessel in the deep white matter. Difficulty controlling hemostasis of these vessels was one of the main causes of postoperative neurological damage. The introduction of non-stick bipolar dramatically improved the outcome of AVM surgery by allowing a more selective resection with a faster and safer surgery.

Obtaining a good hemostasis of the deep vessels is essential to avoid direct damage to the white substance but is also the key to avoiding postoperative hemorrhages. A last detail can be suggested regarding arteriovenous malformations with deep feeders involving branches from the choroidal arteries: When safe, try to reach the ventricle, where the medullary vessels coming from the choroidal arteries are more easily identifiable and controllable.

\section{Postoperative Hematoma}

Postoperative bleeding usually occurs very early, in the first postoperative hours after surgery for arteriovenous malformation. Out of 214 AVM treated in the last 7 years, we had only two episodes of postoperative bleeding that occurred after $24 \mathrm{~h}$.

The main causes of postoperative bleeding are:

- An inaccurate hemostasis of the aforementioned deep feeding vessels.

- A bleeding from a large-sized vessel where coagulation ceases after a while. We experienced re-bleeding from vessels that appeared to be well coagulated and then caused postoperative hematomas. We observed that relevant-sized collateral originated a few millimeters before the previously coagulated end of the cut vessel. The collateral therefore maintained high pressure near a too-short coagulated tract of the vessel. We therefore recommend in these cases to use a micro clip to control the bleeding. It is important to keep a long-coagulated tract of the vessel where the blood can stagnate and then stabilize the clot. If this is not possible, and if the vessel has a significant caliber, it is advisable to use micro clips for AVM to ensure a better seal of the clot.

- A third element that can lead to postoperative bleeding is the presence of a residual of the malformation that has not been removed during surgery because it is hidden by brain tissue. In our experience this has happened close to eloquent areas that we want to preserve, or has been caused by lack of awareness of the full extent of the malformation. The presence of a residual in the postoperative angiography has a high risk of bleeding, so our modus operandi is to return to the operating room and complete the removal of the malformation in the same setting, if this is possible. It is important to reduce intraoperatively the chances that this will occur. Tools that allow us to detect the presence of a hidden residual at the end of the surgical procedure are:

- Intraoperative Fluorangiography (FA) with Indocyanine green is useful to check the flow in the vessels in real time. A recognized limit of FA is that it shows only what is on the surface. What is beyond the surface remains hidden. Nevertheless, the key sign to look for in the presence of a hidden residual of AVM is the early filling of a visible vein in the surgical field [11].

- Intraoperative Ultrasound doppler and enhanced Ultrasound imaging with microbubbles contrast. High definition ultrasound is a new, valuable instrument in the OR. It is cheap and in real time. It can be of valuable in AVM surgery. Doppler ultrasound can show a high flow beyond the surface. The use of contrast with microbubbles allows us to identify beyond the visible surface the possible presence of a small residue. It is a technique that requires training and confidence with the instrument, but can be a precious help [12].

- The intraoperative micro-Doppler can be used to explore the entire surgical cavity. If high flow is identified, it can indicate a residual malformation that is worthwhile to explore [13].

- Obviously the most suitable instrument to identify AVM residuals is a catheter angiography; therefore, a hybrid surgical room equipped with intraoperative angiography represents the best solution. They are rare and only few centers have the luxury of an integrated operating room. If the hybrid O.R. is not available, we suggest obtaining an angiographic 
examination immediately at the end of the surgical procedure even if this may prove time-consuming. The last element that can favor a postoperative bleeding is an increase in the arterial pressure during the postoperative awakening or transport of the patient. During the awakening phase, the patient can feel pain and the arterial pressure can increase, or the patient may cough and increase the venous pressure. Both situations are dangerous when you must rely on fragile vessels just coagulated. For this reason, it is preferable to maintain the patient asleep for at least $12 \mathrm{~h}$ in intensive care, especially in complex malformations and those where intraoperative hemostasis has been more difficult. This allows for the stabilization of the clot in the closed vessels.

\section{Postoperative Hyperemia}

This complication typically occurs 3 or 4 days after the intervention. It is a hemorrhagic infarction of the surrounding brain that progressively evolves and that may require reoperation or even bone-flap removal for brain decompression.

The underling process is explained by three different theories:

- Normal perfusion pressure breakthrough [14, 15]

- Occlusive hyperemia [16]

- Venous engorgement [17-19]

The Normal perfusion pressure breakthrough theory is a term coined by Spetzler in 1978. He used it to indicate a postoperative hyperemia responsible for hemorrhagic infarction. According to the theory developed by Spetzler, the brain tissue around an arteriovenous malformation has lost the ability of self-regulating based on $\mathrm{CO}_{2}$. The chronic dilatation in the presence of chronic ischemia prevents an increase in the resistance of the capillaries once the malformation has been removed. The chronically dilated lowresistance vessels are therefore unable to resist the suddenly increased flow once the flow is redirected in the surrounding tissue after the AVM is removed.

The second theory is the occlusive hyperemia theory, proposed by al-Rodhan in 1993. It is based on two interrelated mechanisms: the first refers to stagnation of the arterial flow in the vessels that previously supplied the malformation and its collaterals; the second refers to an obstruction of the venous drainage in the adjacent brain tissue, resulting in a venous engorgement.

The theory on venous engorgement refers to stagnation only into the venous compartment. This theory was proposed in 1993 by Wilson and sustained by Schaller in 2002 and by D'Aliberti in 2013. If the malformation has one or more large venous outflows, these veins tend to thrombose when the AVM is removed. If these veins drain the venous outflow of the surrounding cerebral parenchyma, thrombosis may extend so as to cause venous outflow obstruction, and therefore venous infarction of the surrounding brain tissue.

In our experience, postoperative hyperemia is a rare phenomenon. Out of 266 cases it occurred only three times. In these three cases there was a large venous pattern that suggested that the third hypothesis may reflect the underlying mechanism best.

We consider it extremely important to pay attention to the venous drainage of arteriovenous malformations. When the cerebral venous discharge involves the large draining veins of the malformation, the surgical risk of having postoperative infarction is relevant. A direct surgical access to the malformation must therefore be evaluated and eventually postponed (Fig. 1). Our strategy, depending on the characteristic of the malformation, is to treat the malformation with an embolization in order to reduce the flow through the vein, and then wait a few months, if possible, to reduce the caliber of the main drainage vein. The second alternative is to treat the malformation with Gamma Knife to reduce the flow, allowing the venous outflow to redistribute. The possible residual can be operated after a few years.

Finally, in a few cases where there was a single large draining vein that collected also normal brain vein drainage and where we were worried that the thrombus can spread to functionally useful veins, we used a technique to reduce the caliber of the main draining vein of the malformation. On four occasions we treated the vein intraoperatively with Tullium laser, shrinking the vein and obtaining a reduction in the caliber to almost half of the diameter. The goal of this procedure was to increase the flow velocity and therefore prevent stagnation and thrombosis in the postoperative period (Fig. 2).

\section{Conclusions}

Surgically related complications in AVM treatment, in many cases, can be avoided by paying attention to details:

1. Careful selection of the patient:

(a) addressing a patient with eloquent AVM to Gamma Knife treatment

(b) preoperative treatment with selective embolization of the accessible deep feeders

(c) preoperative gamma knife or embolize those patient with an over-expressed venous pattern

2. Meticulous coagulation of deep medullary feeders:

(a) Using dirty coagulation

(b) Using dry non-stick coagulation 


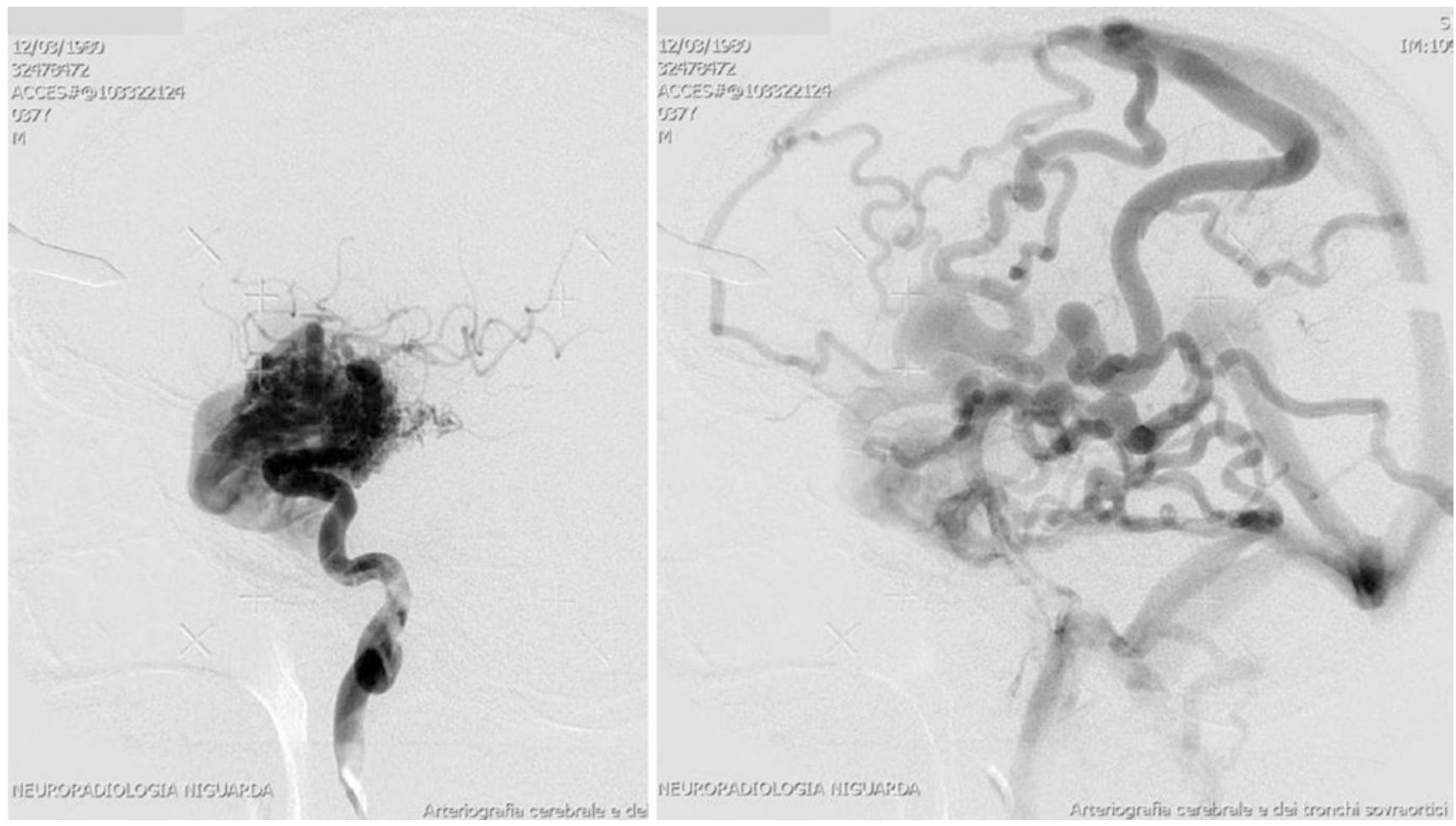

Fig. 1 An overexpressed venous pattern of a small temporal AVM. Resecting the AVM in this case, although technically feasible, is very dangerous due to the high risk of extensive thrombose of the venous network

Fig. 2 Laser shrinkage of the main draining vein to prevent spreading of the thrombus thorough useful draining veins

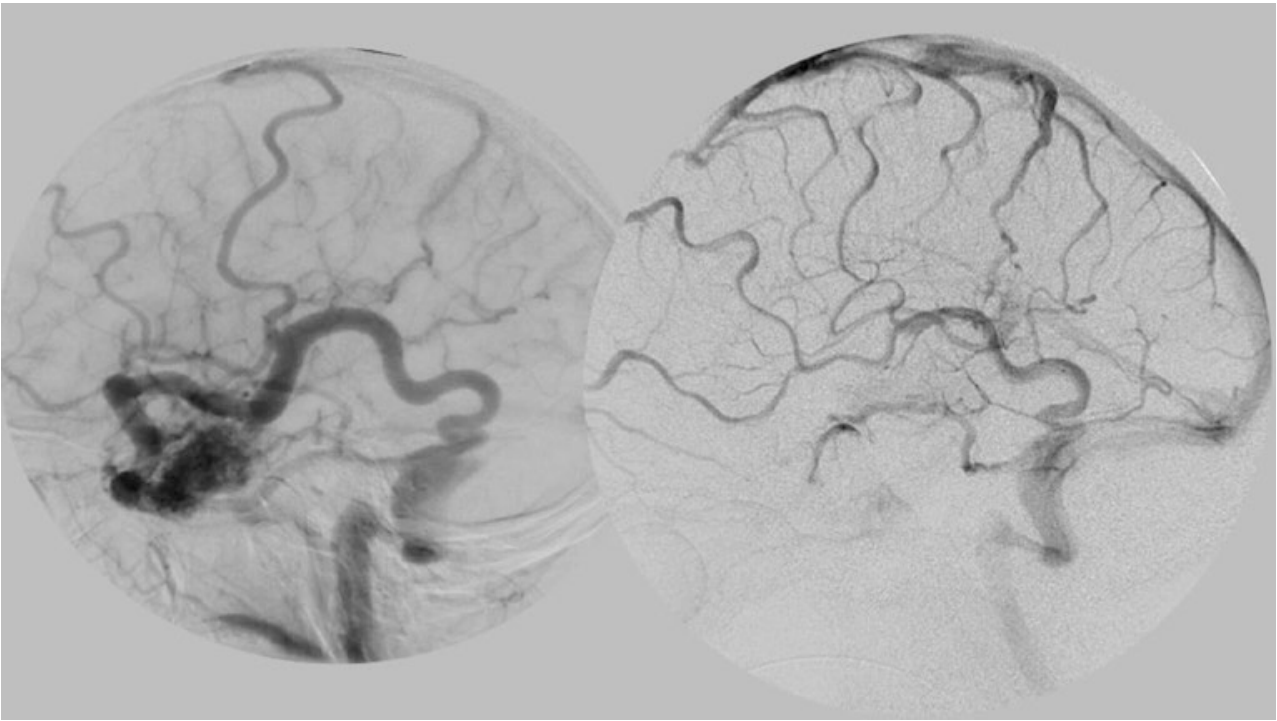

(c) Using micro clips

(d) Using laser

(e) Reaching the choroidal vessel in the ventricle when possible

(f) Avoiding occlusive coagulation with hemostatic agents

3. Check and avoiding any residual of the AVM
4. Keep the patient under pressure control during postoperative period

Fulfilling these steps contributed over time to reduced complications in this difficult surgery, leading to a safer treatment that compares favorably with natural history of brain arteriovenous malformations [20]. 


\section{References}

1. Wang LJ, Lin FX, Zhao B, Wu J, Cao Y, Wang S (2016) Testing the reliability of BOLD-fMRI motor mapping in patients with cerebral arteriovenous malformations by electric cortical stimulation and surgery outcomes. World Neurosurg 92:386-396

2. Kallioniemi E, Pitkänen M, Könönen M, Vanninen R, Julkunen P (2016) Localization of cortical primary motor area of the hand using navigated transcranial magnetic stimulation, BOLD and arterial spin labeling fMRI. J Neurosci Methods 273:138-148

3. Hadjipanayis CG, Levy EI, Niranjan A, Firlik AD, Kondziolka D, Flickinger JC, Lunsford LD (2001) Stereotactic radiosurgery for motor cortex region arteriovenous malformations. Neurosurgery 48(1):70-76. discussion 76-7

4. Lunsford LD, Niranjan A, Kano H, Kondziolka D (2013) The technical evolution of gamma knife radiosurgery for arteriovenous malformations. Prog Neurol Surg 27:22-34

5. Gerrish AC, Thomas AG, Dineen RA (2014) Brain white matter tracts: functional anatomy and clinical relevance. Semin Ultrasound CT MR 35(5):432-444

6. Sarubbo S, De Benedictis A, Merler S, Mandonnet E, Balbi S, Granieri E, Duffau H (2015) Towards a functional atlas of human white matter. Hum Brain Mapp 36(8):3117-3136

7. Cenzato M, Dones F, Boeris D, Marcati E, Fratianni A, Crisà FM, Debernardi A (2018) Contemporary tools in arteriovenous malformations surgery. J Neurosurg Sci 62(4):467-477

8. Kozyrev DA, Thiarawat P, Jahromi BR, Intarakhao P, ChoqueVelasquez J, Hijazy F, Teo MK, Hernesniemi J (2017) "Dirty coagulation" technique as an alternative to microclips for control of bleeding from deep feeders during brain arteriovenous malformation surgery. Acta Neurochir 159(5):855-859

9. Cenzato M, Dones F, Marcati E, Debernardi A, Scerrati A, Piparo M (2017) Use of laser in arteriovenous malformation surgery. World Neurosurg 106:746-749

10. Wu EM, El Ahmadieh TY, McDougall CM, Aoun SG, Mehta N, Neeley OJ, Plitt A, Ban VS, Sillero R, White JA, Batjer HH, Welch BG (2019) Embolization of brain arteriovenous malformations with intent to cure: a systematic review. J Neurosurg 1:1-12

11. Bilbao CJ, Bhalla T, Dalal S, Patel H, Dehdashti AR (2015) Comparison of indocyanine green fluorescent angiography to digi- tal subtraction angiography in brain arteriovenous malformation surgery. Acta Neurochir 157(3):351-359

12. Dellaretti M, Ronconi DE (2019) Intraoperative ultrasound navigation with Doppler function to guide arteriovenous malformation resection: 3-dimensional operative video. Oper Neurosurg (Hagerstown). pii: opz006

13. Burkhardt T, Siasios G, Schmidt NO, Reitz M, Regelsberger J, Westphal M (2015) Intraoperative micro-Doppler in cerebral arteriovenous malformations. J Neurol Surg A Cent Eur Neurosurg 76(6):451-455

14. Rangel-Castilla L, Spetzler RF, Nakaji P (2015) Normal perfusion pressure breakthrough theory: a reappraisal after 35 years. Neurosurg Rev 38(3):399-404. discussion 404-5

15. Spetzler RF, Wilson CB, Weinstein P, Mehdorn M, Townsend J, Telles D (1978) Normal perfusion pressure breakthrough theory. Clin Neurosurg 25:651-672

16. al-Rodhan NR, Sundt TM Jr, Piepgras DG, Nichols DA, Rüfenacht D, Stevens LN (1993) Occlusive hyperemia: a theory for the hemodynamic complications following resection of intracerebral arteriovenous malformations. J Neurosurg 78(2):167-175

17. D'Aliberti G, Talamonti G, Piparo M, Debernardi A, Zella S, Boccardi E, Valvassori L, Nichelatti M (2014) Venous flow rearrangement after treatment of cerebral arteriovenous malformations: a novel approach to evaluate the risks of treatment. World Neurosurg 82(1-2):160-169

18. Schaller C, Urbach H, Schramm J, Meyer B (2002) Role of venous drainage in cerebral arteriovenous malformation surgery, as related to the development of postoperative hyperperfusion injury. Neurosurgery 51(4):921-927. discussion 927-9

19. Wilson CB, Hieshima G (1993) Occlusive hyperemia: a new way to think about an old problem. J Neurosurg 78(2):167-175

20. Cenzato M, Tartara F, D'Aliberti G, Bortolotti C, Cardinale F, Ligarotti G, Debernardi A, Fratianni A, Boccardi E, Stefini R, Zenga F, Boccaletti R, Lanterna A, Pavesi G, Ferroli P, Sturiale C, Ducati A, Cardia A, Piparo M, Valvassori L, Piano M (2018) Unruptured versus ruptured AVMs: outcome analysis from a multicentric consecutive series of 545 surgically treated cases. World Neurosurg 110:e374-e382

Open Access This chapter is licensed under the terms of the Creative Commons Attribution 4.0 International License (http://creativecommons. org/licenses/by/4.0/), which permits use, sharing, adaptation, distribution and reproduction in any medium or format, as long as you give appropriate credit to the original author(s) and the source, provide a link to the Creative Commons license and indicate if changes were made.

The images or other third party material in this chapter are included in the chapter's Creative Commons license, unless indicated otherwise in a credit line to the material. If material is not included in the chapter's Creative Commons license and your intended use is not permitted by statutory regulation or exceeds the permitted use, you will need to obtain permission directly from the copyright holder. 